\title{
Sistem Particle Image Velocimetry Untuk Mengukur Kecepatan Aliran Terbuka
}

\author{
Qathrun Nada Munawaroh ${ }^{1}$, Suhartono ${ }^{2}$, Fatchurrochman ${ }^{3}$
}

\begin{abstract}
This research study about measuring water flow speed in open channel using Particle Image Velocimetry (PIV) to measure flow stream. Research purpose is to measure water flow speed in open channel by analyzing the image. The result shows that RMSE value near to $0 \%$ with detail RMSE $0.13372 \%$ from straight canal water flows, $\mathbf{0 . 1 3 2 6 6 \%}$ from fortex canal water flows and $0.16894 \%$ from canal with pole influence.
\end{abstract}

keywords Particle Image Velocimetry (PIV); water flow speed; open channel.

Abstrak- Aliran saluran terbuka adalah saluran yang mengalirkan air dengan permukaan bebas. Saluran terbuka dapat terjadi dalam bentuk yang bervariasi cukup besar, mulai dari aliran di atas permukaan tanah yang terjadi pada waktu hujan sampai aliran dengan kedalaman prismatis. Perubahan kecepatan aliran merupakan salah satu faktor yang menentukan keadaan, sifat aliran dan pengaruh terhadap tingginya permukaan aliran. Perkembangan teknologi membantu pengukuran kecepatan aliran dengan tidak mengganggu aliran yang sedang terjadi, agar data yang dihasilkan lebih akurat. Maka pada penelitian ini menggunakan rekaman gambar aliran untuk dianalisis sesuai dengan metode Particle Image Velocimetry (PIV). Percobaan pada penelitian ini dilakukan pada 3 bentuk aliran, yaitu aliran pada saluran lurus, aliran vortex dan aliran dengan pengaruh pilar. Tujuan penelitian ini adalah untuk mengetahui pengukuran kecepatan aliran terbuka menggunakan metode PIV (Particle Image Velocimetry) dengan proses analisa dari data gambar. Hasil penelitian menunjukkan bahwa pengukuran kecepatan aliran dengan metode

Qathrun Nada Munawaroh is with the Informatic Engineering Departement of Universitas Islam Negeri Maulana Malik Ibrahim Malang, Indonesia, (email qathrun.nadha@gmail.com)

Fresy Nugroho is with the Informatic Engineering Departement of Universitas Islam Negeri Maulana Malik Ibrahim Malang, Indonesia.

Muhammad Faisal is is the Informatic Engineering Departement of Universitas Islam Negeri Maulana Malik Ibrahim Malang, Indonesia.
Particle Image Velocimetry memiliki hasil nilai RMSE yang mendekati $0 \%$. Pada percobaan analisis aliran pada saluran lurus menghasilkan nilai RMSE $\mathbf{0 . 1 3 3 7 2} \%$, aliran vortex $\mathbf{0 . 1 3 2 6 6 \%}$ dan pada aliran dengan pengaruh pilar yaitu $0.16894 \%$.

Kata Kunci-Particle Image Velocimetry (PIV); Kecepatan; Aliran Terbuka.

\section{PENDAhUluan}

Aliran saluran terbuka adalah saluran yang mengalirkan air dengan permukaan bebas. Saluran terbuka dapat terjadi dalam bentuk yang bervariasi cukup besar, mulai dari aliran di atas permukaan tanah yang terjadi pada waktu hujan sampai aliran dengan kedalaman air konstan dalam saluran prismatis. Mekanika aliran saluran terbuka lebih sulit dibanding dengan mekanika saluran tertutup. Aliran saluran terbuka memiliki permukaan bebas yang dipengaruhi oleh tekanan udara, sedangkan pada aliran tertutup alirannya terkurung dalam ruang sehingga tidak dapat terpengaruhi langsung oleh tekanan udara kecuali tekanan hidrolik. Salah satu contoh saluran terbuka yang dijumpai adalah sungai. Sungai merupakan tipe umum dari saluran terbuka namun memiliki bentuk penampang melintang yang tidak teratur.

Saluran terbuka memiliki berbagai macam karakteristik yang diklasifikasikan, hal ini untuk mempermudah mengetahui bentuk aliran yang terjadi. Karakteristik aliran dapat diketahui dengan melakukan pengukuran kecepatan aliran. Kondisi aliran dalam saluran terbuka yang rumit berdasarkan kenyataan bahwa kedudukan permukaan yang bebas cenderung berubah sesuai waktu, ruang, kedalaman aliran, debit, kemiringan dasar saluran yang tergantung satu sama lain. Perubahan setiap parameter saluran yang saling berkombinasi akan mempengaruhi kecepatan yang terjadi. Perubahan kecepatan tersebut menentukan keadaan, sifat aliran dan pengaruh terhadap ketinggian permukaan [1]. Perubahan kecepatan yang menetukan keadaan, sifat aliran dan pengaruh terhadap ketinggian permukaan dapat digunakan oleh BNPB (Badan Nasional Penanggulangan Bencana) untuk mengetahui bencana alam yang dapat terjadi, seperti banjir. Ketika kondisi kecepatan aliran rendah maka peluang terjadinya bencana banjir rendah. Sedangkan ketika kondisi kecepatan aliran tinggi maka peluang terjadinya bencana banjir juga tinggi. 
Berdasarkan permasalahan diatas, dibutuhkan sebuah metode yang efektif dalam pengukuran. Metode yang berkembang mengikuti instrumen alat ukur aliran fluida semakin banyak, diantaranya Laser Doppler Velocimetry (LDV), Acoustic Doppler Velocimetry $(A D V)$ dan Particle Image Velocimetry (PIV). Metodemetode instrumen alat ukur tersebut mempunyai pendekatan yang berbeda-beda untuk menghitung kecepatan aliran fluida. Metode LDV dan ADV dapat digunakan untuk mengukur pada satu titik saja saat tertentu. Sedangkan metode PIV mampu memetakan vektor kecepatan sesaat aliran pada semua titik yang ditangkap oleh kamera.

\section{LANDASAN TEORI}

Penelitian terkait yang pernah dilakukan yaitu pada penelitian yang mengenai aliran air di saluran terbuka yang dilakukan oleh Indra Setia Puta pada tahun. Tujuan dari penelitian ini adalah untuk mengetahui pengelolaan sungai, pengembangan sungai dan pengendalian daya rusak sungai dengan melakukan pengukuran kecepatan[2]. Penelitian terkait yang lain yaitu untuk mengetahui distribusi kecepatan aliran permukaan di sekitar pilar dengan melihat fenomena perubahan aliran dengan pengamatan visual. Penelitian ini mengukur kecepatan dengan penggunaan partikel untuk mendapatkan arah [3]. Penelitian terkait terdahulu yang lain tentang penggunaan metode Particle Image Velocimetry berbasis pengolahan citra yaitu pengukuran dilakukan dengan image processing rekaman aliran. Hasil dari penelitian ini adalah mengetahui vektor kecepatan aliran dengan $80 \%$ kebenaran dan nilai RMSE 3,5\% [4].

\section{PERANCANGAN SISTEM}

\section{A. Deskripsi Data}

Data yang direkam dengan kamera dioperasikan dalam mode pengambilan gambar berurutan dengan jarak antar pengambilan gambar maksimum 1/40 detik. Data citra tersebut selanjutnya akan diproses dengan pengolahan citra untuk menghitung kecepatan gerakan partikel. Pengukuran diperlukan minimal dua gambar yang terekam dalam selang waktu yang berbeda. Maka perpindahan partikel gambar 1 ke gambar 2 dapat diketahui jarak dan arahnya dengan membagi jarak dan waktu sampling dapat diketahui kecepatan sesaat partikel uji yang dapat merepresentasikan kecepatan aliran.

Data yang akan digunakan dalam penelitian yaitu diambil dari laboratory PIV yang dapat diakses pada website https://pivlab.blogspot.com. Data gambar yang diambil yaitu citra berukuran 600x800 dengan format .bmp, gambar ini sudah dilakukan image preprocessing. Dalam penggunaan analisis, data citra yang digunakan yaitu berpasangan tidak hanya satu frame, akan tetapi menggunakan beberapa frame untuk dipasangkan sesuai dengan urutan waktu. Data gambar ini memiliki frame rate atau jumlah bingkai frame yang ditunjukkan setiap detik dan memiliki satuan frame per second (fps). Semakin tinggi nilai pixel dalam frame maka semakin baik kualitas gambar untuk dianalisis.

\section{B. Sampling Rate}

Sampling rate adalah berapa banyaknya jumlah sample yang diambil dalam satuan waktu (detik). Kecepatan pengambilan sample harus memenuhi kriteria tertentu. Pada penelitian ini menggunakan format gambar yang diambil merupakan hasil konversi sebuah video menjadi gambar. Sehingga menghasilkan gambar dalam waktu berurutan yang halus dan memiliki interogasi besar. Data yang digunakan untuk percobaan penilitian ini diambil dari laboratory PIV yang memiliki data-data gambar aliran.

Hasil pengambilan gambar tersebut, kemudian dilakukan proses image preprocessing untuk mendapatkan gambar yang bisa dianalisis dalam sistem Format gambar yang diinputkan dalam sistem PIV yaitu:

Tabel 1. Format File yang Digunakan.

Nama File Nama Panjang $\quad$ Format File

TIFF

Tagged Image File tif .tiff

Format

JPEG

Join Photographics

.jpeg .jpg

Expret's Group

GIF

Graphics Interchange

.gif

Format

$\begin{array}{lll}\text { BMP } & \text { Windows Bitmap } & \text {.bmp } \\ \text { PNG } & \text { Portable Network } & \text {.png }\end{array}$

Grapichs

XWD

X-window Dump

.xwd

\section{Perancangan Sistem}

Proses dalam sistem ini memiliki dua proses utama. Yang pertama adalah proses data training dan kedua adalah proses data testing. Proses data training dimulai dengan hasil rekaman gambar gerakan partikel pada aliran model fisik. Setelah itu pre-processing yang terdiri dari proses akuisisi citra, penyeimbangan histrogram, intensitas pencahayaan dan intensitas capping. Pre-processing akan memproses data gambar yang akan dimasukkan pengolahan citra. Selanjutnya, setiap citra yang menghasilkan nilai pixel yang mengandung informasi lokasi titik dan data warna atau intensitas kecerahan. Karna mengukur kecepatan atau gerak partikel, maka dilakukan proses testing untuk mengurangkan nilai titik pada frame satu dengan nilai titik pada frame yang lain berurutan.

Proses selanjutnya yaitu proses data testing. Proses ini dimulai dari akuisisi citra. Kemudia dilakukan preprocessing yang sama seperti proses data training dan dilakukan pengolahan citra. Selanjutnya dilakukan matriks korelasi data training dan hasil pengolahan citra data testing. Hasilnya adalah nilai pixel yang akan 
dilakukan image evaluation. Dari image evaluation setelah peak finding, dapat dilakukan validasi, interpolasi dan smoothing. Selanjutnya proses dilakukannya eksplorasi data untuk mendapatkan vektor kecepatan. Hasil dari proses tersebut adalah berupa vektor kecepatan aliran yang sesuai dengan pengukuran pada model fisik aliran.

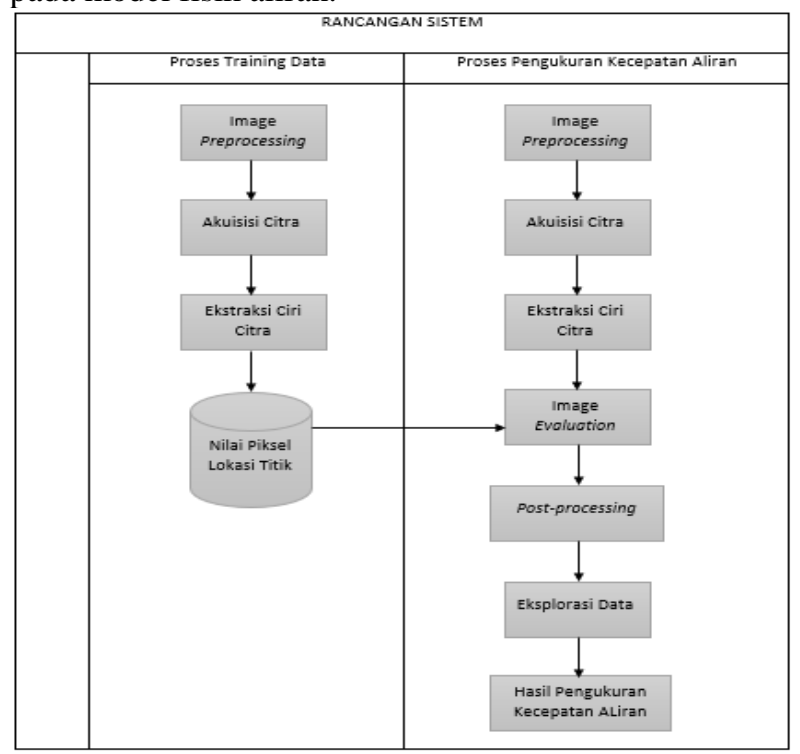

Gambar 1. Perancangan Sistem.

\section{PEMBAHASAN}

Bagian analisis yang dilakukan pada Particle Image Velocimetry adalah algoritma korelasi silang. Pada sub-gambar kecil-kecil (interrogation areas) dari gambar yang terekam dilakukan korelasi silang untuk mendapatkan yang paling memungkinkan perpindahan partikel pada area yang diteliti (interrogation areas). Korelasi silang adalah pola statistik yang mencoba pencocokan pola partikel dari area A kembali di area B. Teknik statistik ini diimplementasikan dengan diskrit fungsi lintas korelasi.

$$
C(m, n)=\sum i \sum j A(i, j) B(i-m, j-n)
$$

Dimana A dan B berada di tempat interogasi yang sama gambar A dan gambar B. Lokasi puncak koordinat intensitas dalam menghasilkan korelasi matriks $\mathrm{C}$ memberikan perpindahan partikel yang paling mungkin dari A ke B.

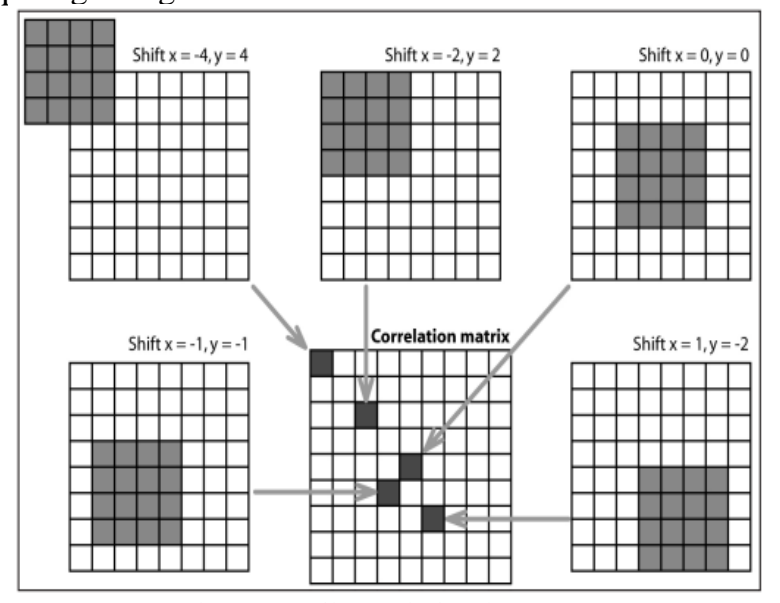

Gambar 2. Matrik Korelasi pada MATLAB.
Ada dua pendekatan umum untuk menyelesaikan persamaan (1):

1. Pendekatan yang paling mudah adalah menghitung matriks korelasi dalam domain spasial seperti pada Gambar 2 pendekatan ini disebut korelasi silang langsung, gambar partikel pencocokan pola dan penyaringan konvolusi.

2. Pendekatan dengan matriks korelasi dalam domain frekuensi Discrate Fourier Transformasi (DFT). Perhitungan menggunakan transformasi fourier cepat. Sehingga perhitungan dapat dilakukan dengan waktu yang singkat.

Mengukur jarak dengan perhitungan korelasi silang mengetahui variable jarak dan waktu partikel yang bergerak mengikuti pola aliran yang telah didapatkan pada pengolahan gambar. Perhitungan dilakukan dengan menggeser pixel per pixel gambar A dan gambar B yang akan menghasilkan gambar $\mathrm{C}$.

$\mathrm{B}(\mathrm{x}, \mathrm{y})$ berukuran $5 \times 5$ dan $\mathrm{A}(\mathrm{x}, \mathrm{y})$ berukuran $3 \times 3$ sebagai berikut :

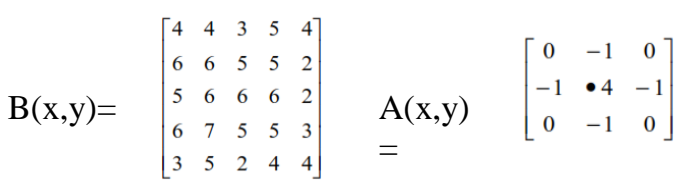

Ket : Tanda (.) menyatakan $(0,0)$ sebuah kernel $\mathrm{B}(\mathrm{x}, \mathrm{y}) * \mathrm{~A}(\mathrm{x}, \mathrm{y})$

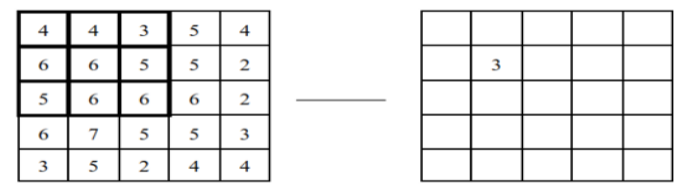

Hasil 3 diperoleh dari $=$

$(0 \times 4)+(-1 \times 4)+(0 \times 3)+(-1 \times 6)+(4 \times 6)+(-1 \times 5)+(0 \times 5)+(-$

$1 \times 6)+(0 \times 6)=3$.

Untuk menghitung nilai sebelahnya maka dilakukan dengan menggeser ke kanan satu pixel dan dilakukan sama untuk nilai sebelahnya. Nilai pixel yang bawah dilakukan dengan menggeser ke bawah satu pixel dan mengulangi langkah yang sama seperti sebelumnya sehingga didapatkan hasil sebagai berikut :

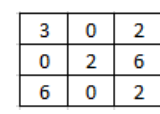
maka untuk C $(x, y)=$\begin{tabular}{|c|c|c|c|c|}
\hline 4 & 4 & 3 & 5 & 4 \\
\hline 6 & 3 & 0 & 2 & 2 \\
\hline 5 & 0 & 2 & 6 & 2 \\
\hline 6 & 6 & 0 & 2 & 3 \\
\hline 3 & 5 & 2 & 4 & 4 \\
\hline
\end{tabular}

Pada dataset Discrate Fourier Transformation memiliki beberapa analisis. Integer hasil analisis pertama digunakan untuk mengimbangi area interogasi pada analisis berikutnya. Hilangnya informasi karena perpindahan partikel yang terjadi, maka area interogasi diminimalkan. Kotak interogasi dapat disempurnakan dengan setiap gambar yang dianalisis dengan menghasilkan resolusi spasial tinggi pada peta vektor akhir bersama dengan rentang kecepatan dinamis yang 
tinggi dan rasio sinyal terhadap noise yang optimal. Dalam aliran flow, pola partikel juga menjadi tolak ukur, gerakan partikel yang tidak seragam akan memperluas puncak intensitas dalam matriks korelasi dan memperburuk hasilnya.

Perhitungan digunakan untuk mengubah domain spasial pada citra menjadi domain frekwensi. Analisa yang digunakan seperti filtering. Dengan menggunakan transformasi fourier citra dapat dilihat dalam domain frekwensi. Hal ini bertujuan untuk memperceptak waktu perhitungan yang dilakukan dengan metode korelasi silang. Untuk menghitung Discrate Fourier Transformation maka perlu dilakukan perhitungan juga dengan fast fourier transform.

Pada perhitungan Tranformasi Fourier dilakukan perhitungan sebagai berikut :

Diket $\mathrm{B}(\mathrm{x}, \mathrm{y})$ adalah sebagai berikut :

\begin{tabular}{|l|l|l|l|l|l|}
\hline 0 & 1 & 1 & 1 & 1 & 0 \\
\hline 1 & 1 & 0 & 0 & 1 & 1 \\
\hline 1 & 1 & 0 & 0 & 1 & 1 \\
\hline 0 & 1 & 1 & 1 & 1 & 0 \\
\hline
\end{tabular}

Bila digambarkan hasilnya sebagai berikut :

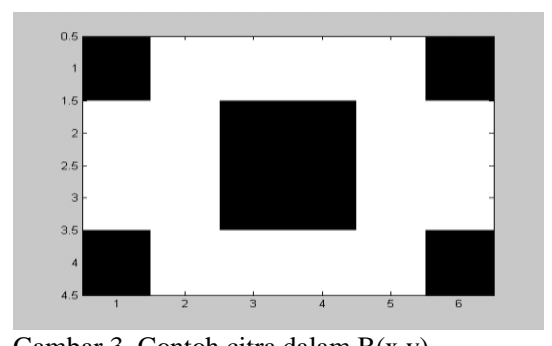

Gambar 3. Contoh citra dalam B(x,y).

DFT dari fungsi tersebut yaitu :

$$
F\left(k_{1}, k_{2}\right)=\sum_{n_{1}=0}^{4} \sum_{n_{2}=0}^{6} f\left(n_{1}, n_{2}\right) \cdot e^{-j 2 \pi T\left(k_{1} n_{1} / 4+k_{2} n_{2} / 6\right)}
$$

Hasil dari DFT adalah sebagai berikut :

\begin{tabular}{|c|c|c|c|c|c|}
\hline 16 & 0 & $\begin{array}{c}-2- \\
3.46 \mathrm{i}\end{array}$ & 0 & $\begin{array}{c}-2+ \\
3.46 \mathrm{i}\end{array}$ & 0 \\
\hline 0 & $\begin{array}{c}-1.27- \\
4.73 \mathrm{i}\end{array}$ & 0 & 0 & 0 & $\begin{array}{c}4.73- \\
1.27 \mathrm{i}\end{array}$ \\
\hline 0 & 0 & 0 & 0 & 0 & 0 \\
\hline 0 & $-4.73+$ & 0 & 0 & 0 & $\begin{array}{c}1.27+ \\
4.73 \mathrm{i}\end{array}$ \\
\hline
\end{tabular}

Jumlah perhitungan DFT di atas adalah $(4 \times 6)^{2}=576$ kali.

Dengan menggunakan FFT, maka perhitungannya adalah:

(1) Hitung DFT untuk ukuran $4 \times 4$ sehingga diperoleh :

$$
\begin{array}{ll}
F(0,0)=16 & F(0,1)=0 \\
F(0,2)=-2-3.46 i \quad F(0,3)=0 \\
F(1,0)=0 & F(1,1)=-1.27-4.73 i \\
F(1,2)=0 & F(1,3)=0 \\
F(2,0)=0 & F(2,1)=0 \\
F(2,2)=0 & F(2,3)=0 \\
F(3,0)=0 & F(3,1)=-4.73+1.27 i \\
F(3,2)=0 & F(3,3)=0
\end{array}
$$

(2) Dengan cara konjugate dapat diperoleh :

$\mathrm{F}(0,4)=$ conjugate $(\mathrm{F}(0,2))=-2+3.46 \mathrm{i}$

$\mathrm{F}(0,5)=$ conjugate $(\mathrm{F}(0,1))=0$

$\mathrm{F}(1,4)=$ conjugate $(\mathrm{F}(3,2))=0$

$\mathrm{F}(1,5)=$ conjugate $(\mathrm{F}(3,1))=-4.73-1.27 \mathrm{i}$

$\mathrm{F}(2,4)=$ conjugate $(\mathrm{F}(2,2))=0$

$\mathrm{F}(2,5)=$ conjugate $(\mathrm{F}(2,1))=0$

$\mathrm{F}(2,4)=$ conjugate $(\mathrm{F}(1,2))=0$

$\mathrm{F}(2,5)=$ conjugate $(\mathrm{F}(1,1))=-1.27+4.73 \mathrm{i}$

Jumlah perhitungan dari FFT berukuran $\mathrm{m} \times \mathrm{n}$ adalah $(\mathrm{m} / 2+1) \times(\mathrm{n} / 2+1) \times \mathrm{m} \times \mathrm{n}+\mathrm{m} \times \mathrm{n} / 4$

$=(4 / 2+1) \times(6 / 2+1) \times 4 \times 6+4 \times 6 / 4$

\begin{tabular}{|c|c|c|c|c|c|c|c|c|}
\hline \multirow[t]{4}{*}{ No. } & \multicolumn{4}{|c|}{ Koordinat Titik (cm) } & \multirow{3}{*}{$\begin{array}{c}\text { Jarak x } \\
(\mathrm{m})\end{array}$} & \multirow{3}{*}{$\begin{array}{c}\text { Jarak y } \\
(\mathrm{m})\end{array}$} & \multirow{3}{*}{$\begin{array}{l}\text { Perpindahan } \\
\text { (m) }\end{array}$} & \multirow{3}{*}{$\begin{array}{r}\text { Kecepatan } \\
\text { (m/detik) }\end{array}$} \\
\hline & \multicolumn{2}{|c|}{ Gambar 1} & \multicolumn{2}{|c|}{ Gambar 2} & & & & \\
\hline & $\mathrm{X}$ & $\mathrm{Y}$ & $\mathrm{X}$ & $\mathrm{Y}$ & & & & \\
\hline & {$[1]$} & [2] & [3] & [4] & $\begin{array}{c}{[5]=(\mid[1]-} \\
[3] \mid) / 100\end{array}$ & $\begin{array}{c}{[6]=\mid[2]-} \\
{[4] / / 100}\end{array}$ & $\begin{array}{c}{[7]=} \\
\sqrt{[5]^{2}+[6]^{2}}\end{array}$ & {$[8]=[7] / t$} \\
\hline 1 & 30.5 & 1 & 32.5 & 1 & 0.02 & 0 & 0.0200 & 0.1111 \\
\hline 2 & 30 & 2.5 & 31.5 & 3 & 0.015 & 0.005 & 0.0158 & 0.0878 \\
\hline 3 & 30 & 5 & 36.5 & 5 & 0.065 & 0 & 0.0650 & 0.3611 \\
\hline 4 & 29.5 & 8 & 34 & 8 & 0.045 & 0 & 0.0450 & 0.2500 \\
\hline
\end{tabular}

$=(3 \times 4 \times 4 \times 6)+(4 \times 6 / 4)$

$=294 \mathrm{kali}$

Hasil pengukuran kecepatan diperoleh dari nilai pergeseran pixel dari gambar 1 ke gambar lainnya. Kemudian dilakukan perhitungan metode silang yang akan mendapatkan nilai titik koordinat, jarak dan perpindahan seperti pada Tabel 2 beikut :

Tabel 2. Hasil Perhitungan Metode Korelasi Silang.

Dalam sistem yang akan dibuat hasil dari besarnya kecepatan akan ditampilkan dalam bentuk frekuensi untuk membaca kecepatan dalam setiap frame yang diperoleh.

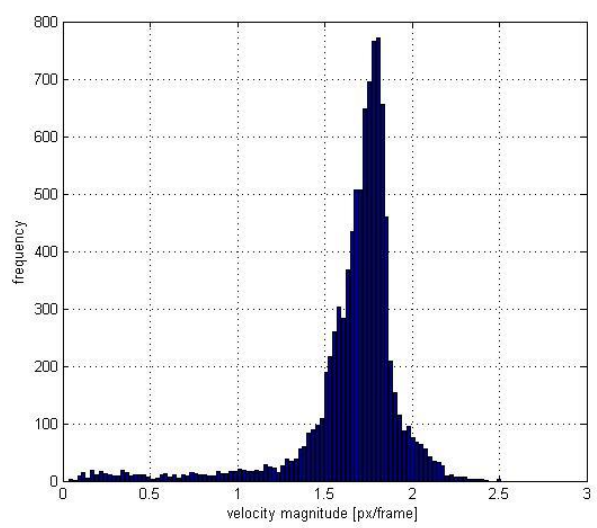

Gambar 4. Histogram Hasil Pengukuran Kecepatan.

Pengujian pada sistem yang dibangun pada penelitian ini dilakukan untuk mengetahui keakurasian data kecepatan aliran terbuka. Sistem Particle Image Velocimetry ini menggunakan metode Transformasi Fourier dengan Fast Fourier Transformasion. 
Data input gambar dalam sistem diatur dengan urutan squel 1-2,2-3,... untuk mendapatkan hasil dengan urutan waktu yang beruntun. Pada percobaan ini aliran yang diteliti terdapat tiga bentuk aliran, yaitu aliran pada saluran yang lurus, aliran dengan pengaruh pilar dan aliran pada saluran vortex.

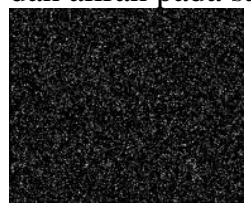

1)Aliran Lurus

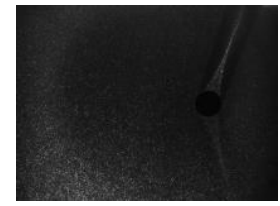

2)Aliran dengan Pilar

Gambar 5. Bentuk Aliran untuk Data Input.

\section{A. Aliran Lurus}

Percobaan yang dilakukan pada aliran dengan saluran yang lurus akan dianalisis tanpa menggunakan area pengecualian. Area interogasi dalam saluran yang lurus memiliki vektor yang dapat dianalisis sebagai berikut :

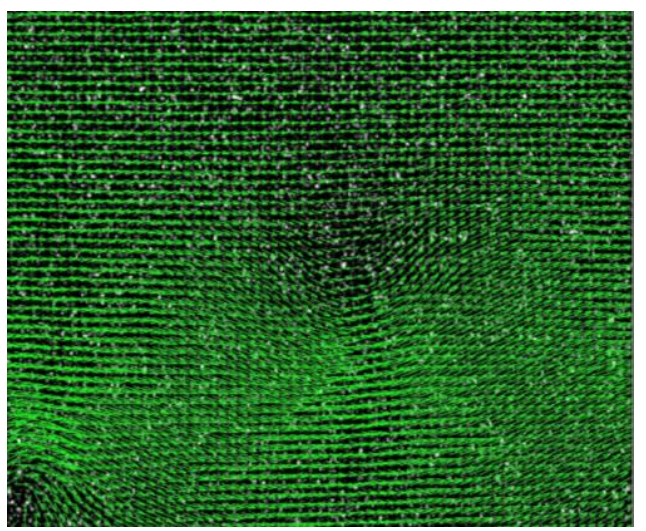

Gambar 6. Analisis PIV dalam Saluran Lurus.

Gambar 6 menunjukkan arah aliran yang bergerak dari satu arah. Selanjutnya dilakukan kalibrasi pada citra untuk mengetahui keakurasian terhadap gambar nyata. Calibration tersebut dilakukan dengan perbandingan terhadap gambar yang belum dilakukan analisis atau dengan pembuatan jarak yang dibuat dengan parameter terhadap jarak nyata dengan satuan milimeter. Berikut merupakan Calibration pada saluran lurus :

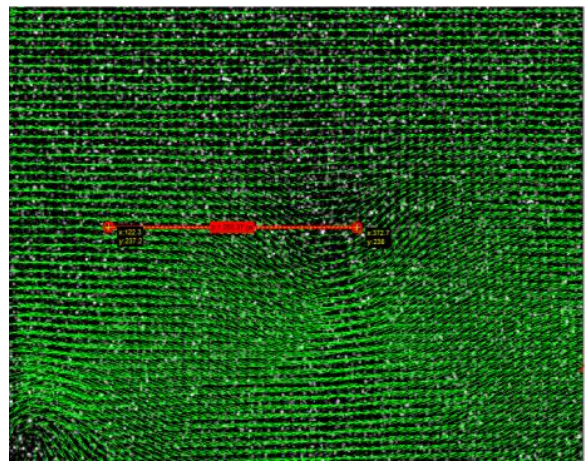

Gambar 7. Calibration pada Saluran Lurus

Hasil tersebut akan dilakukan skala data dalam satuan px/frame untuk mengetahui kecepatan dalam histogramnya. Berikut merupakan hasil skala data dan juga validasi terhadap data dengan satuan $p x /$ frame :

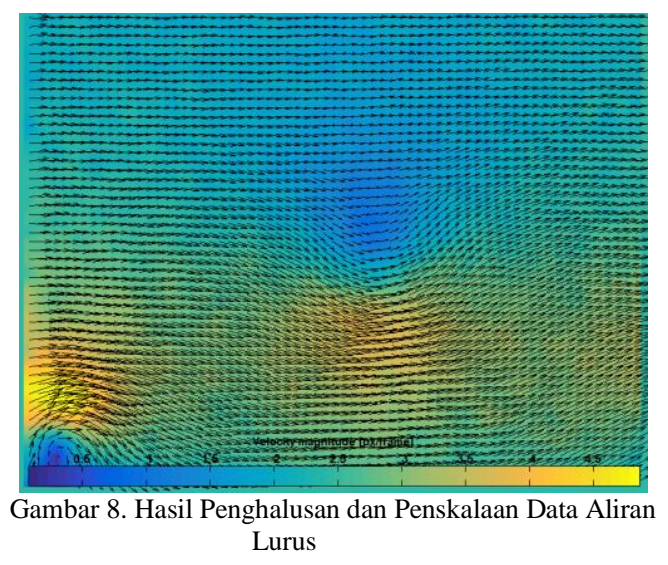

Besarnya kecepetan aliran dalam setiap frame kemudian ditunjukkan dengan histogram seperti pada gambar berikut :

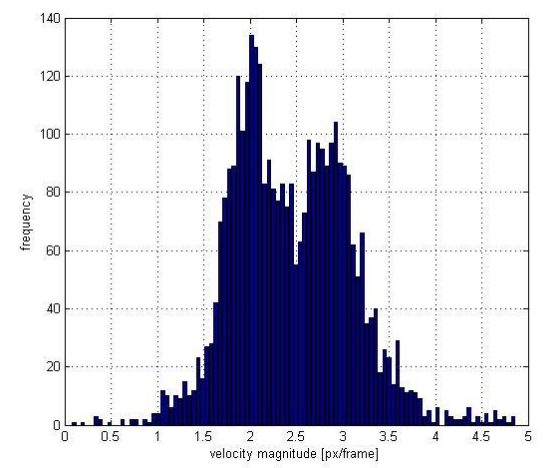

Gambar 9. Histogram Aliran Lurus

Sedangkan percobaan perhitungan kecepatan aliran lurus pada sistem memiliki hasil yang ditunjukkan pada Tabel 3 berikut.

Tabel 3. Hasil Perhitungan Kecepatan Aliran Lurus pada Sistem.

\begin{tabular}{|c|c|c|c|c|c|c|}
\hline \multirow{4}{*}{ No. } & \multicolumn{4}{|c|}{ Koordinat Titik $(\mathrm{cm})$} & \multirow{4}{*}{$\mathrm{S}(\mathrm{px})$} & \multirow{3}{*}{$\begin{array}{c}\text { Kecepatan } \\
(\mathrm{m} / \mathrm{s})\end{array}$} \\
\hline & \multicolumn{2}{|c|}{ Gambar 1} & \multicolumn{2}{|c|}{ Gambar 2} & & \\
\hline & $\mathrm{x}$ & Y & $\mathrm{X}$ & $\mathrm{Y}$ & & \\
\hline & [1] & [2] & [3] & [4] & & $1 \mathrm{px} /$ frame \\
\hline 1 & 351.6 & 274.2 & 233 & 205.5 & 137.13 & 0.00182 \\
\hline 2 & 478.5 & 248 & 350.8 & 205.5 & 134.83 & 0.00278 \\
\hline 3 & 480.1 & 70.5 & 244.5 & 63.9 & 235.77 & 0.00159 \\
\hline 4 & 434.3 & 405.2 & 269.8 & 370.8 & 168.04 & 0.00223 \\
\hline \multicolumn{6}{|c|}{ Jumlah } & 0.00842 \\
\hline \multicolumn{6}{|c|}{ Rata-rata } & 0.002105 \\
\hline \multicolumn{6}{|c|}{ Standar Deviasi } & 0.00257 \\
\hline
\end{tabular}

\section{B. Aliran Vortex}

Percobaan yang dilakukan pada aliran vortex akan dianalisis tanpa menggunakan area pengecualian. Area interogasi dalam saluran yang lurus memiliki vektor yang dapat dianalisis sebagai berikut : 


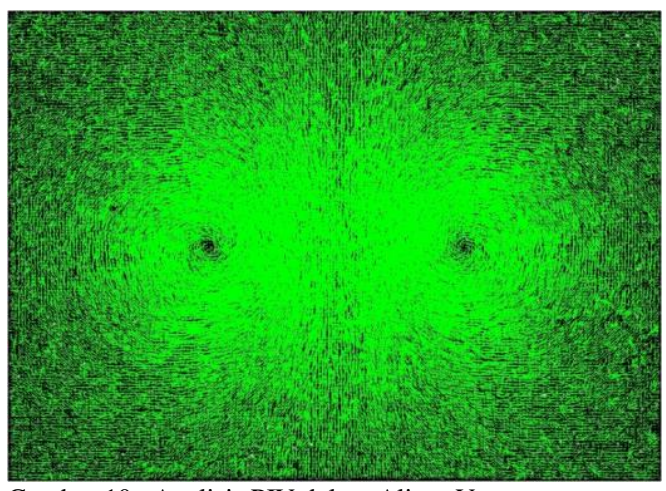

Gambar 10. Analisis PIV dalam Aliran Vortex.

Berdasarkan Gambar 10 hasil analisis transformasi fourier dan analisis kecepatan aliran yang melalui proses seperti aliran di saluran lurus. Kemudian gambar dilakukan validasi atau Calibration yang bertujuan untuk mendapatkan faktor skala perbandingan antara satuan milimeter pada model real terhadap satuan pixel gambar yang diimpor sebagai data input.

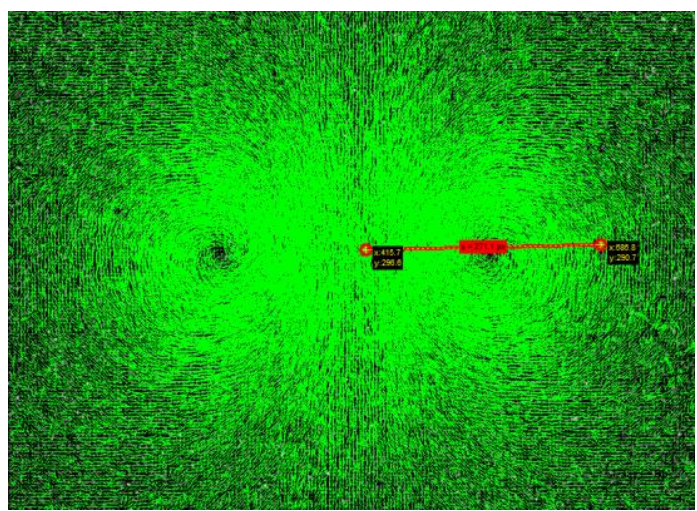

Gambar 11. Hasil Calibration terhadap Jarak Nyata.

Selanjutnya, dapat dilakukan validasi data untuk mengetahui beberapa vektor yang salah. Vektor yang salah akan muncul karena daerah yang mendapatkan penerangan yang buruk pada gambar. Beberapa cara untuk memfilter data yaitu dapat dari penetapan batas kecepatan. Selain itu pemfilteran data dapat dilakukan dengan menentukan deviasi standar. Vektor yang diinterpolasi akan berwarna oren. Hal ini merupakan langkah opsional dalam sistem PIV. Berikut merupakan hasil vortisitas atau penskalaan data.

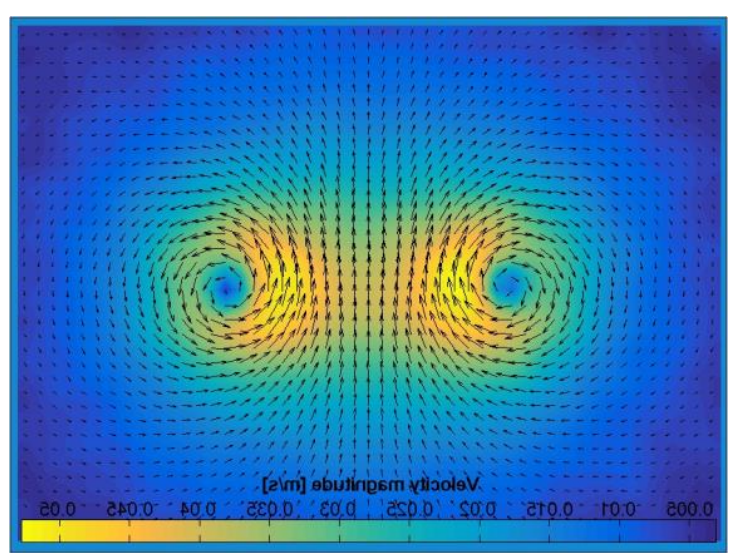

Gambar 12. Hasil penghalusan dan Penskalaan Data Aliran Vortex.
Hasil kecepatan aliran dapat dinyatakan dalam histogram yang menunjukkan frekuensi setiap besarnya kecepatan. Frekuensi tersebut merupakan jumlah besarnya kecepatan dalam setiap frame. Hasil kecepatan aliran ditunjukkan seperti pada Gambar 13 berikut.

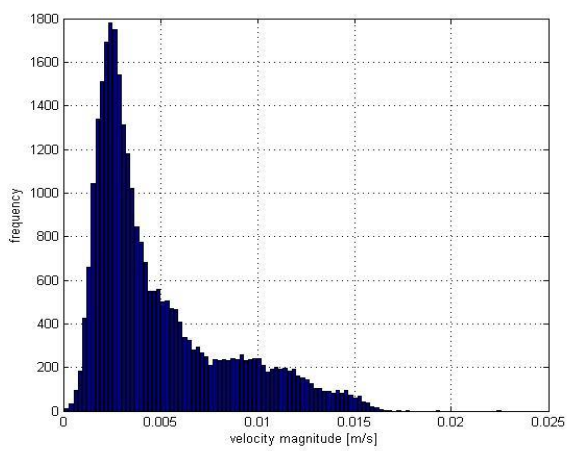

Gambar 13. Histogram Kecepatan Aliran Vortex.

Berdasarkan hasil analisis pada frame maka dapat diperoleh perhitungan kecepatan aliran dengan mengetahui titik koordinat pada gambar. Perhitungan manual yang dilakukan pada aliran saluran lurus meghasilkan seperti pada Tabel 4 berikut.

Tabel 4. Hasil Perhitungan Kecepatan Manual pada Aliran Vortex

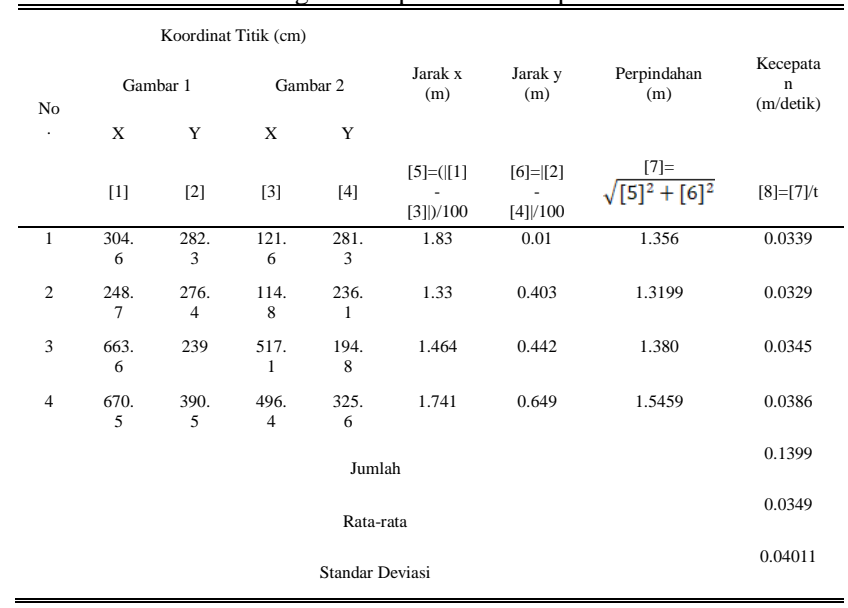

Sedangkan percobaan perhitungan kecepatan aliran vortex pada sistem memiliki hasil yang ditunjukkan pada Tabel 5 berikut.

Tabel 5. Hasil Perhitungan Kecepatan Aliran Vortex pada Sistem

\begin{tabular}{|c|c|c|c|c|c|c|}
\hline \multirow{4}{*}{ No. } & \multicolumn{4}{|c|}{ Koordinat Titik $(\mathrm{cm})$} & \multirow{4}{*}{$\mathrm{S}(\mathrm{px})$} & \multirow{4}{*}{$\begin{array}{l}\text { Kecepatan } \\
(\mathrm{m} / \mathrm{s})\end{array}$} \\
\hline & \multicolumn{2}{|c|}{ Gambar 1} & \multicolumn{2}{|c|}{ Gambar 2} & & \\
\hline & $\mathrm{X}$ & $\mathrm{Y}$ & $\mathrm{X}$ & $\mathrm{Y}$ & & \\
\hline & [1] & [2] & & [4] & & \\
\hline 1 & 304.6 & 282.3 & 121.6 & 281.3 & 182.95 & 0.00205 \\
\hline 2 & 248.7 & 276.4 & 114.8 & 236.1 & 188.1 & 0.00199 \\
\hline 3 & 663.6 & 239 & 517.1 & 194.8 & 153.1 & 0.00245 \\
\hline 4 & 670.5 & 390.5 & 496.4 & 325.6 & 185.81 & 0.00202 \\
\hline \multicolumn{6}{|c|}{ Jumlah } & 0.00851 \\
\hline \multicolumn{6}{|c|}{ Rata-rata } & 0.00212 \\
\hline \multicolumn{6}{|c|}{ Standar Deviasi } & 0.00259 \\
\hline
\end{tabular}




\section{Aliran dengan Pengaruh Pilar}

Percobaan yang dilakukan pada aliran pilar akan dianalisis sesuia dengan pilar yang menjadi pengaruh kecepatan aliran. Area interogasi dalam saluran yang memiliki pilar memiliki pengecualian pada objek pilar tersebut, maka vector aliran yang dapat dianalisis adalah sebagai berikut :

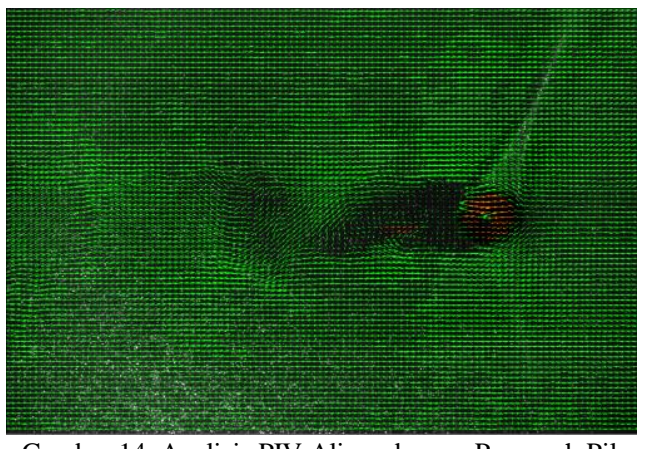

Gambar 14. Analisis PIV Aliran dengan Pengaruh Pilar.

Selanjutnya dilakukan kalibrasi pada citra untuk mengetahui keakurasian terhadap gambar nyata. Calibration tersebut dilakukan dengan perbandingan terhadap gambar yang belum dilakukan analisis atau dengan pembuatan jarak yang dibuat dengan parameter terhadap jarak nyata dengan satuan milimeter. Berikut merupakan Calibration pada aliran yang dipengaruhi pilar yang ditunjukkan pada Gambar 4.16 dengan poisis titik X 749.6 sampai 749.6 dan titik Y 231.4 sampai 513.6 maka diperoleh waktu tempuh $\mathrm{s}=282.23 \mathrm{px}$ yang akan diimplementasikan pada jarak nyata $\mathrm{m} / \mathrm{s}$ :

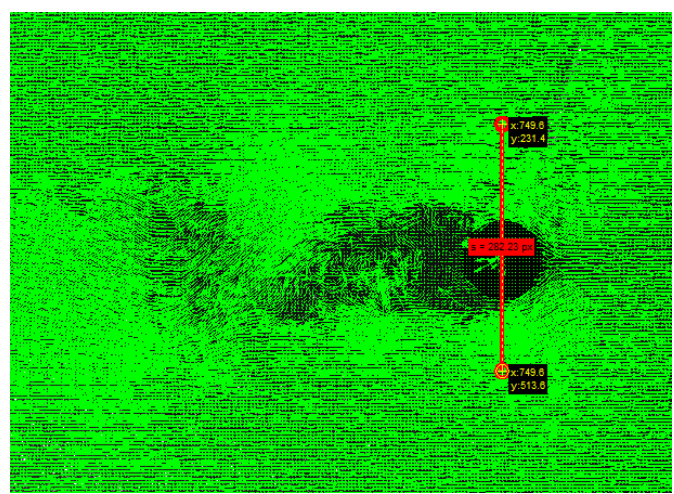

Gambar 15. Calibration Aliran dengan Pengaruh Pilar.

Hasil tersebut akan dilakukan skala data dalam satuan px/frame untuk mengetahui kecepatan dalam histogramnya. Berikut merupakan hasil skala data dan juga validasi terhadap data dengan satuan $p x /$ frame :

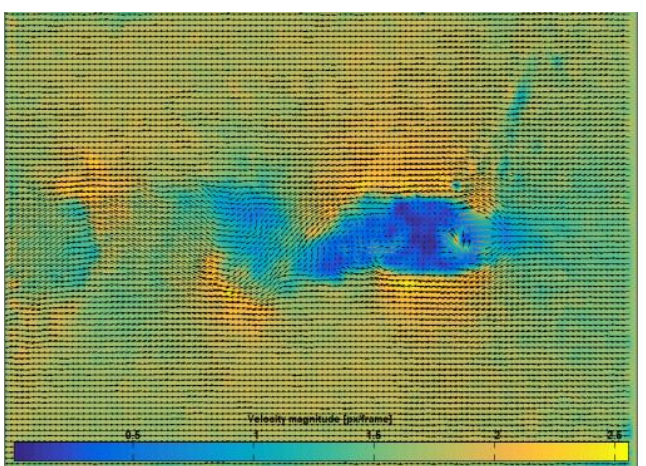

Gambar 16. Hasil Penghalusan dan Penskalaan Data Aliran dengan Pengaruh Pilar.
Selanjutnya, hasil dari skala data tersebut akan mendapatkan histogram kecepatan dengan domain frekuensi setiap framenya.

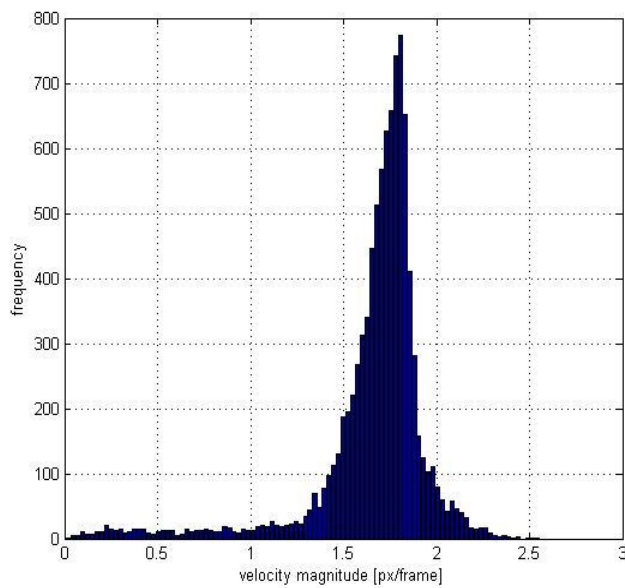

Gambar 17. Histogram Kecepatan Aliran dengan Pengaruh Pilar

Berdasarkan hasil analisis pada frame maka dapat diperoleh perhitungan kecepatan aliran dengan mengetahui titik koordinat pada gambar. Perhitungan manual yang dilakukan pada aliran saluran lurus meghasilkan seperti pada Tabel 6 berikut.

Tabel 6. Hasil Perhitungan Kecepatan Manual pada Aliran dengan

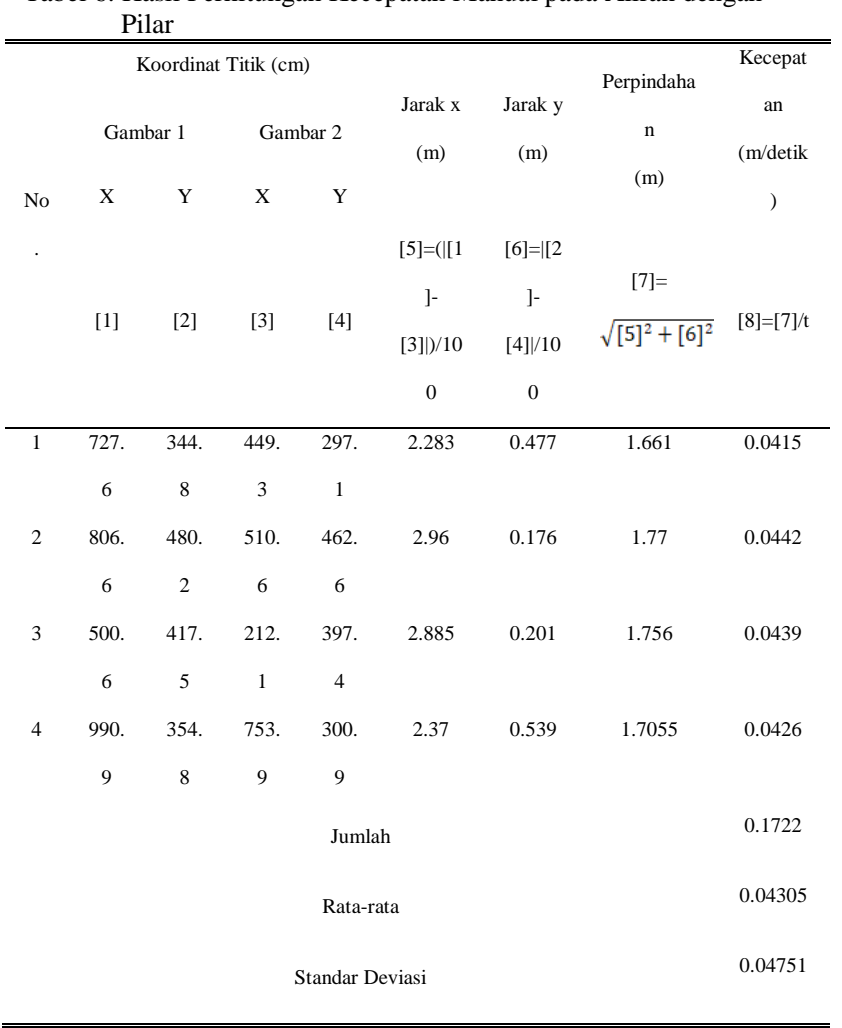

Sedangkan percobaan perhitungan kecepatan aliran dengan pengaruh pilar pada sistem memiliki hasil yang ditunjukkan pada Tabel 7 berikut. 
Tabel 7. Hasil Perhitungan Kecepatan Aliran dengan Pilar pada Sistem

\begin{tabular}{|c|c|c|c|c|c|c|}
\hline \multirow{4}{*}{ No. } & \multicolumn{4}{|c|}{ Koordinat Titik (cm) } & \multirow{4}{*}{$\mathrm{S}(\mathrm{px})$} & \multirow{4}{*}{$\begin{array}{c}\text { Kecepatan } \\
\text { (m/s) } \\
\\
1 \\
\text { px/frame }\end{array}$} \\
\hline & \multicolumn{2}{|c|}{ Gambar 1} & \multicolumn{2}{|c|}{ Gambar 2} & & \\
\hline & $\mathrm{X}$ & $\mathrm{Y}$ & $\mathrm{X}$ & $\mathrm{Y}$ & & \\
\hline & [1] & [2] & [3] & [4] & & \\
\hline 1 & 727.6 & 344.8 & 449.3 & 297.1 & 233.17 & 0.00161 \\
\hline 2 & 806.6 & 480.2 & 510.6 & 462.6 & 296.44 & 0.00126 \\
\hline 3 & 500.6 & 417.5 & 212.1 & 397.4 & 289.14 & 0.0013 \\
\hline 4 & 990.9 & 354.8 & 753.9 & 300.9 & 243..08 & 0.00154 \\
\hline \multicolumn{6}{|c|}{ Jumlah } & 0.00571 \\
\hline \multicolumn{6}{|c|}{ Rata-rata } & 0.00142 \\
\hline \multicolumn{6}{|c|}{ Standar Deviasi } & 0.00896 \\
\hline
\end{tabular}

\section{KESIMPULAN}

Berdasarkan hasil uji coba penelitian dan pembahasan mengenai pengukuran kecepatan aliran terbuka menggunakan metode Particle Image Velocimetry dan pendekatan algoritma Discrate Fourier Transformation dan dilakukan kompeksitas menggunakan algoritma Fast Fourier Tranformation, dapat ditarik kesimpulan bahwa pengukuran kecepatan aliran pada 3 bentuk aliran yaitu, aliran di saluran lurus, aliran vortexdan aliran denganpengaruh pilar. Pada aliran di saluran lurus perhitungan dilakukan dalam waktu 00.00.21 yang mampu menganalisis arah vektor kecepatan aliran dalam 4 frame. 4 frame tersebut merupakan gambar yang berpasangan yang diambil dalam waktu beruntun atau berurutan. Gambar yang dianalisis memiliki resolusi yang tinggi yaitu 640 x 480 pixel, semakin besar resolusi gambar maka semakin akurat analisis gerak partikel dalam gambar yang menjadi titik koordinat.
Dalam perhitungan kecepatan aliran yang dilakukan pada sistem ini menghasilkan data dalam histogram untuk membaca pola besarnya kecepatan yang telah diperoleh. Besar kecepatan dinyatakan dalam satuan $\mathrm{m} / \mathrm{s}$ dan ditampilkan dalam bentuk frekuensi. Hasi perhitungan dengan metode PIV dan pendekatan algorimta DFT dan FFT tersebut dilakukan proses pengujian sistem untuk mengetahui nilai keakurasian sistem. Perhitungan akurasi tiap-tiap aliran menghasilkan nilai RMSE $0.13372 \%$ pada aliran di saluran lurus, $0.13266 \%$ pada aliran vortex dan $0.16894 \%$. Dalam preferensi penilaian menggunakan RSME memiliki hasil mendekati nol adalah yang terbaik. Sedangkan hasil yang didapatkan mendekati 0 , maka dari nilai performa RMSE sistem memiliki keakuratan data.

\section{REFERENSI}

[1] Triatmodjo, B. (1996). Mekanika Fluida. Yogyakarta: Beta Offset.

[2] Putra, I. S. (2015). Studi Pengukuran Kecepatan Aliran Pada Sungai Pasang Surut. Jurnal Teknik, 33-46.

[3] Mokobombang S. R., H. P. (2013). Analisa Vekto Kecepatan dan Pola Aliran di Sekitar Pilar dengan MEtode PIV (Particle Image Velocimetry). Jurnal Teknik Sipil, 1-9.

[4] Raharjo P. A., B. R. (2011). Pengembangan Particle Image velocimetry (PIV) Berbasis Pengolahan Citra untuk Pengukuran Aliran 2D. Journal Annual Engginering, 42-49. 